\title{
AVANÇOS E RETROCESSOS NAS POLÍTICAS DE ENCARCERAMENTO NA AMÉRICA DO SUL
}

\author{
Advances and setbacks in imprisonment policies in South America
}

SOZZO, Máximo (org.) Postneoliberalismo y penalidad en América del Sur'. Buenos Aires, CLACSO, 2016.

Rogério do Nascimento Carvalho

O livro trata do crescimento das taxas de encarceramento em fins do século XX e início do século XXI, na América do Sul, em especial, nas pesquisas apresentadas no Brasil, Venezuela, Equador e Argentina. A característica especial destes países foi a ascensão de governos de esquerda ao comando do poder, durante o início deste século.

Os autores buscam mostrar que a aliança política local, feita por governos de esquerda ao assumirem o poder, buscou dar ruptura as regras penais e processuais penais vigentes, para obter resultados positivos e, por conseguinte, a diminuição no número de detenções, evitando as superlotações dos presídios.

O propósito da obra é apresentar como a transição de governos de cunho liberal nestes países e sua maior intervenção na economia, auxiliam na construção de uma identidade pós-liberal e nas mudanças de rumo na adoção de políticas penais e processuais que refletem diretamente no insucesso, quando da análise temporal das medidas adotadas.

Trata-se de uma obra dirigida a acadêmicos e profissionais das áreas de Sociologia, Direito e Ciências Sociais, de fácil entendimento de conteúdo, que é organizado de maneira coerente com a exibição temporal de cada país e, consequente concatenação dos fatos que auxiliam ou não no sucesso da

\footnotetext{
${ }_{1}^{1}$ Nota do editor: recentemente, foi publicada uma tradução dessa obra para a língua portuguesa. (ver SOZZO, 2017).

2 Mestre em Política e Estratégia Marítima do PPGEM da Escola de Guerra Naval, pesquisador do Grupo de Pesquisa Genocídio e Massacres na Era Contemporânea da Universidade Federal de São Paulo (Unifesp) e professor da faculdade de direito da Faculdade de Caldas Novas (Unicaldas). E-mail: rogertheone@gmail.com.
} 
adoção políticas penais e processuais dos governos que são conhecidos como "pós-liberais".

Estas pesquisas ocorrem em momentos históricos próximos e prescindem da compreensão do leitor para as particularidades de cada caso - apesar de apresentarem na mesma direção de mudança de contraponto ao sistema vigente. Entretanto, verifica-se que a assunção destes governos pósliberais apresentou números iniciais que apontavam sucesso na adoção de uma politica mais flexivel, mas que ao passar de poucos anos revelou-se ineficiente. Por isso, a necessidade de estudos sobre a relação de politicas e penalidades, a influência de atores na tomada de rumos de formulação e aplicação destas políticas, que vão desde juízes, promotores, policiais, diretores de estabelecimentos penitenciários e guardas que influem no resultado da aplicação legal ao caso concreto.

Por ser uma política de governo, está sujeito a constantes mudanças, seja de aperfeiçoamento ou de correção de rumo, a depender das mudanças políticas pontuais, visando a construção da maioria, por exemplo, das casas legislativas.

A estrutura da obra apresenta a divisão didática dos casos que envolvem o Brasil, Venezuela, Equador e Argentina.

Azevedo e Cifali abrem a explanação intitulada "Seguridad Publica, politica criminal y penalidad durante los gobernos Lula y Dilma (2003-2014) Cambios y continuidades", apresentando a evolução do crescimento das taxas de homicídios no país desde a década de 1980, composta basicamente pelo grupo masculino, negro e que reside na periferia dos centros urbanos. $\mathrm{O}$ que leva a atuação, já na década de 1990, sob o governo do Presidente Fernando Henrique Cardoso (1995-2002) a reagir frente ao quadro de crise de Segurança Pública.

Outrossim, a eleição do Presidente Lula (2003-2010) inova a atuação no campo da Segurança Pública através de ações permeadas nitidamente da área social. Por maior que seja a ambiguidade politica na coalizão de sustentação do governo, a direção da política petista, buscou dar ênfase na diminuição das desigualdades como resposta assertiva ante ao problema da violência crescente, com consequentes investimentos em programas sociais, 
porém, não se esquecendo de ações que objetivaram as politicas de controle de armas, combate as impunidades de crimes praticados por organizações criminais contrárias aos movimentos sociais e aos direitos humanos; bem como aperfeiçoar os órgãos de segurança pública, aplicando nas demais unidades da Federação.

Contudo, houve problemas na adoção dessas políticas, em especial, o PRONASCI - Programa Nacional de Segurança Pública com Cidadania, que envolvia a adoção de questões socioculturais na coletividade com fulcro em reduzir a criminalidade com envolvimento da comunidade cidadã e com valorização dos profissionais que trabalham com segurança pública. É necessário analisar a relação violência e criminalidade, porém, não obtém êxito devido a precariedade das ações efetuadas, bem como a ausência de uma reforma estrutural das organizações de segurança pública.

Dentre as reformas no Diploma Legal durante este período destacamse a aprovação do Estatuto do Desarmamento (Lei 10826/2003), Lei Maria da Penha - Violência contra a Mulher (Lei 11340/2006), Nova Lei das Drogas (Lei $11343 / 2006$ ) e Lei de Medidas Cautelares no processo penal (Lei $12403 / 2011)$.

Apesar das inovações trazidas pelos diplomas legais acima mencionados é válido considerar a falta de estrutura na segurança pública, que ao se utilizar de duas polícias (civil e militar) permite a perpetuação da violência e da corrupção, uma vez que, também é falho o sistema de controle externo destas corporações. Inadequado também se mostra o poder judicial que não consegue esclarecer, em tempo hábil, os delitos recorrentes, enquanto as manobras processuais existentes demonstram à sociedade o retrato da impunidade, que é traduzido por presídios ocupados por presos preventivos ou aqueles de menor potencial ofensivo, vítimas muitas vezes de organização criminosa.

Batista (2012) aponta que a prisão ganha exponencial importância pois está acima do delito e, a retirada de cidadãos do meio social, notadamente de classes inferiores, atende à política vigente de restrição ao trabalho informal nas grandes cidades, fazendo com que estas pessoas sejam encarceradas para a garantia do bem comum, ou seja, o uso mais 
intensivo de mudança das leis penais para solução dos conflitos na contramão do que inicialmente era preconizados pelos governos do Partido dos Trabalhadores no Brasil.

Capítulo seguinte, Grajales e Hernández apresentam sua contribuição intitulada “Chavismo y Politica Penal (1999- 2017)”. A análise pontua a crise econômica vivida pela Venezuela por sucessivos governos democráticos que precisavam recorrer as normas do Fundo Monetário Internacional (FMI) que levou a adoção de normas neoliberais e, assim agravar o crescimento da pobreza e da desigualdade. É neste panorama que emerge Hugo Chávez Farias e que vence as eleições presenciais, depois de tentar um golpe de Estado, em 1992. A lógica chavista busca a regeneração política e a criação de um Estado mais justo, visto que o presidente não adveio das fileiras partidárias da esquerda tradicional e nem de movimentos sociais, porém adota estas bandeiras e direciona na adoção do socialismo boliviano.

Dividido em quatro etapas temporais, a apresentação, inicia-se no período de 1999/2000 onde a adoção do Código Orgânico Processual Penal (COPP), oriundo do governo anterior, significou a forte redução da taxa de encarceramento, sobretudo pela mudança da natureza para acusatória do processo penal que prevê o julgamento em liberdade como regra geral, o que foi mantido com a assunção da Constituição da República Boliviana da Venezuela submetida a referendo popular.

Todavia, a adoção COPP não foi suficiente para diminuir a taxa de criminalidade e, conseguinte, a sensação de inseguridade junta a população, levou a Assembleia Nacional a reformar o Código Penal e o COPP, restringindo beneficios processuais, bem como tipificando novas condutas e na majoração de penas, ocorridas na segunda etapa que compreende os anos de 2000-2005.

Para Chávez, a mudança deveria partir do melhoramento da redistribuição de renda, expressando sua rejeição quanto as mudanças legislativas, que significou o retrocesso do garantismo penal na Venezuela, confirmado pelo Tribunal Supremo de Justiça.

Já na terceira etapa, que compreende os anos de 2006-2012, foi marcada por sucessivas reformas do $\operatorname{COPP}(2006,2008,2009,2012)$ que 
não significou a melhoria do sistema carcerário, que mantinha os números ascendentes, levando o próprio Chávez a reconhecer que adoção de políticas sociais não bastaria para impelir o crescimento dos índices de delinquências no país.

Com a morte de Chávez, Nicolás Maduro o sucede na presidência em escrutínio realizado em abril de 2013. No periodo de 2013-2014, o Governo se vê obrigado a tomar medidas contra a insegurança e a criminalidade, haja vista o crescimento das taxas de encarceramento e da taxa de homicídios, sobretudo oriundos da crise econômica que afeta o país.

No tocante ao caso do Equador, Paladinos apresenta no artigo intitulado "La 'mano dura' de la revolución ciudadana" como se configurou o processo que levou a ascensão de Rafael Correa à presidência daquele país, oriundo da crise internacional e econômica, denominada como a larga norte neoliberal (LNN).

Já em posse do mandato presidencial, Correa obtém os melhores resultados da América Latina, na redução da desigualdade, conjugado sobretudo na adoção de programa Revolución Ciudadana que prevê a atuação do poder público em obras de infraestrutura, o que serviu para mostrar o contraponto ao período precedente neoliberal instável. Com este êxito, Correa busca a adoção de nova Constituição, em 2008, que privilegia o pacto do "bom viver", fruto das tradições ancestrais indígenas e que aponta o sucesso do consistente crescimento econômico vivido pelo país daquele momento.

A política penal, no entanto, vive dois momentos marcantes, o primeiro "estados de garantias" (2007-2009) consubstanciado do aprofundamento do estado constitucional de direitos e justiça. No segundo momento, denominado "estado de polícia", fruto da tentativa de um golpe de estado frustrado, em 2010, levou as reformas cujo marco de inflexão foi o aumento das penas com a adoção do COIP (Código Orgânico Integral Penal) que ocasionou o endurecimento do giro punitivo e da perda do horizonte da esquerda equatoriana no governo. Reaproximando-se das políticas defenestradas da LNN, como efeito bumerangue, sobretudo ao olhar a sociedade equatoriana e aos políticos locais percebe-se o descompasso 
proposto no primeiro período da Revolución Ciudadana, o que justifica a contrarreforma e o endurecimento penal.

Prossegue a obra analisando o artigo de Sozzo "Postneoliberalismo y politica penal en la Argentina (2003-2014)". Reflexo das eleições de 2003, que levou a assunção de Nestor Kirchner à presidência daquele país sob a batuta da defesa da questão social em detrimento das políticas neoliberais adotadas pelos governos antecessores de Menem e de Fernando de La Rua e pela construção das alianças com grupos ligados a defesa dos direitos humanos.

O "Kirchnerismo" período do governo de Néstor Kirchner e que fora sucedido por sua mulher Cristina Fernández de Kirchner busca a aproximação com os governos da Venezuela e do Brasil em conotação política similar e o consequente não alinhamento com os Estados Unidos da América.

Com o início do mandato presidencial frágil, Néstor Kirchner se apoia nos movimentos sociais, pois the convém este apoio e, assim aplicar as mudanças legais visando endurecer as regras penais e processuais advindos da Cruzada Axel que provocou o impulso para a mudança legais no país.

Outrossim, com o fortalecimento obtido nas urnas, nas eleições de 2005, resultado obtido sobretudo pela recuperação econômica que marcou a guinada pelo endurecimento penal, sem debates com a sociedade, o que ocorreu no momento em que o Kirchnerismo não gozava mais da estabilidade política e, assim, busca no incremento da punição e do endurecimento policial como meio de ofertar respostas à sociedade argentina, novamente combalida pela crise econômica que se iniciava no país.

Membros próximos a presidente Cristina Fernández de Kirchner se mostravam favoráveis a adoção de medidas mais duras como forma de responder aos anseios da população, visando angariar dividendos políticos nas provincias e na sustentação da coalizão presidencial.

A obra se aproxima de autores como Batista (2012) aduz que o aumento da sensação de violência e a resposta de sucessivos governos em matéria criminal tem sido influenciada pelo vigor da politica econômica que, influenciada pelo acúmulo de capital do empresariado, pode determinar 
maior ou menor grau de flexibilização da norma penal bem como dos estabelecimentos prisionais. Tendo como exemplo, o âmago de sucessivos governos brasileiros em atender a influência do mercado privado e que resultou no aumento do encarceramento no Brasil no período dos governos FHC e Lula. Este aumento está correlacionado à junção dos anseios do mercado, da mídia e do capital financeiro e que decorre no acirramento da punição de delitos de menor potencial ofensivo que, ao atender interesses capitalistas necessita que a sociedade seja permanentemente vigiada em nome da segurança, porém acompanhada de controle social.

Como se pode observar, nos artigos que compõem a presente obra é peculiar o traço comum que as une: o aumento do encarceramento encontra consonância de problemas de ordem econômica e politica interna vividos pelos países, que teve o fito de retroceder em flexibilizar o sistema penal, endurecendo-o no intuito de atender a interesses de fulcro econômicofinanceiro. Identificar e reconhecer esta mudança é passo primordial para compreender o aumento do encarceramento nos países aqui estudados, bem como de reconstruir, no futuro próximo, uma sociedade com maior consciência de seu papel e, assim, menos injusta e arbitrária.

Por enquanto, no presente, há de se considerar a grande influência do capital volátil internacional, das grandes empresas e empresários no sentido de influenciar os ditames das políticas soberanas das nações, o que causa distorções na aplicação das leis e sua consequente marginalização e visibilidade de determinados grupos sociais, neste caso dos mais humildes e de baixo poder aquisitivo, que são oprimidos em nome da construção do Estado de segurança capitaneado por dirigentes que mantém para si o interesse econômico e político, distinto daqueles que efetivamente o constroem.

\section{Referências:}

BATISTA, Vera Malaguti. Introdução crítica à criminologia brasileira. 2a. ed. Rio de Janeiro: Revan, 2012.

SOZZO, Máximo (org.) Pós-neoliberalismo e penalidade na América do

Sul. São Paulo: Fundação Perseu Abramo, 2017. 